\title{
Boundary Characteristic Research of Green Manufacturing System
}

\author{
Ping Tao, Gang Zhao \\ Key Laboratory of Metallurgical Equipment and Control Technology of Ministry of Education \\ Wuhan University of Science and Technology \\ Wuhan, Hubei 430081
}

\begin{abstract}
It is of utmost importance for the analysis and construction of green manufacturing system to correctly recognize the boundary of the green manufacturing system. This article firstly expounds the concepts of manufacturing system boundaries. Through the analysis of resources and environmental constraints for manufacturing system, we describe the boundary and those dynamic characteristics of green manufacturing system within the resource and environmental constraints. It is also given a defined thinking about the boundary of green manufacturing system in the paper.
\end{abstract}

Keywords-System boundary; Green manufacturing system; Constraint

\section{INTRODUCTION}

Green manufacturing system is a modern manufacturing system that comprehensively considers optimizing the utilization of resources and the environmental impact. Due to inconsistency on understanding of it, further investigation is still regular. The understanding of the analysis and construction of green manufacturing system to correctly recognize the boundary of the green manufacturing system is a crucial step, and it can help us define the relationship between the green manufacturing system and the outside world better. It is of utmost importance to the optimization of green manufacturing system.

\section{THE CONCEPT AND CHARACTERISTICS OF SYSTEM BOUNDARIES}

System is an organic integrity with specific functions, and it is made up of the combination of several factors which are interacted and interdependent. Environment is the umbrella term of many related factors existing around the system such as material, economy, information, and interpersonal relationship. There exists a system boundary between the environment and system [1]. Every system has its own boundary which isolates itself from the environment. The impact of the environment on the system must be through the system boundary, and vice versa.

According to the boundary theory of shell [2], Boundary has the following characteristics:

- The universality of the Boundary;

- The particularity in space;

- Constraining force to input and output of system;
- The intermediary;

- Non-arbitrariness.

Boundary has two main roles:

- Boundary is just a boundary between the included functions but not included in system. This kind of defense is done by some control or restraint.

- Boundary makes some exchange interaction between system and environment. Such as manufacturing system produces waste through its border to nature, and nature inputs material, energy and information etc to the manufacturing system through the manufacturing system.

\section{GREEN MANUFACTURING SYSTEM BOUNDARIES BASED ON RESOURCES AND ENVIRONMENTAL CONSTRAINTS}

Green manufacturing system is an input/output system where the manufacturing resources will enter and eventually be formed as green products through green manufacturing process [3], and it construct the system with economic benefit and social benefit coordinated optimization. The boundary of the green manufacturing system is the boundary between green manufacturing system and its surrounding environment. The surrounding environment of green manufacturing system mainly includes the market condition, economic environment, natural resources environment, ecological environment and other peripheral environments.

Because of many factors of external environment can affect the system, if all things were considered, that will lead to the system boundary big, complex and difficult to define. So we should focus on the great influential factors of green manufacturing system and through reasonable choice to determine the boundary of green manufacturing system.

The existence and operation of every manufacturing system are restricted by the market condition, the most important restricted factor of market condition to green manufacturing system is the utilization of resources and the impact on the ecological environment [4].The product market competitiveness decision of the green manufacturing system depends on the green degree of the product, that is, the degree of effects of resource utilization on the ecological environment. 
Manufacturing resources are the foundations of the survival of manufacturing systems, especially the material and energy resource are the important foundations of the survival and development of manufacturing systems. Material and energy resource mainly include raw materials, Land resources, water resources forest resources and mineral resources, etc. With the rapid growth of economy, the manufacturing has been plundering for limited resources, which leads to the rapid consumption of natural resources, and low utilization of resource contributes to the waste of resources and excessive consumption. Currently, manufacturing resources lack the conflicts led between resource and manufacturing development, and manufacturing resources has become the important constraint for the survival and development of green manufacturing system, the key constraint is the material energy resources constraint.

Ecological environment provides the raw materials and energy resources for the development of manufacturing industries, and also offer a space carrier for the waste of systems and human activities. But the ability of the environment to support the operation of the manufacturing system is limited. When the effect that operation of the manufacturing system has on the environment is beyond environmental affordability, all kinds of environmental problems will be caused, such as water pollution, air pollution, noise pollution and dust pollution, etc. Manufacturing system is not only large resource consumption, but the pollution of ecological environment. Thus, the restrictions of manufacturing environment on manufacturing systems request that the traditional manufacturing system must be transformed to the green manufacturing system, and manufacturing environmental factors are the important elements for green manufacturing system characteristics in the process of manufacturing.

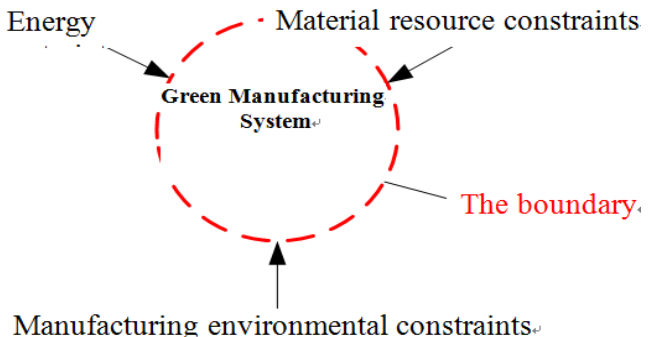

Fig. 1. Green manufacturing system boundary based on resources and environmental constraints

The above shows that green manufacturing system boundary is actually a special control and constraint to green manufacturing system. Green manufacturing system defends green features by its border, border plays a crucial role to the survival and operation of the green manufacturing system. The existence and operation of the green manufacturing system depends on the constraints of manufacturing resources and manufacturing environment, the "resources" in green manufacturing refers to material resources whose focus is on material resources and energy [5]. Manufacturing environment refers to the manufacturing process of the general environment (such as ecological environment, occupational health, etc.), so the key environmental factors affects green manufacturing system are manufacturing resources and manufacturing environment. Based on considerations of resources and environmental problems, material resources constraints, energy constraints and manufacturing environmental constraints codetermine the green manufacturing system boundary, which is shown in Figure 1.

\section{DYNAMIC CHARACTERISTICS OF GREEN MANUFACTURING SYSTEM BOUNDARIES}

Green manufacturing system is an open system, and its system boundary is also a dynamic boundary [6]. With the development of green manufacturing system from primary to advanced stage, resources and environmental constraints have been intensifying as well as the boundaries of green manufacturing system are in the dynamic development process.

At the initial stage of the green manufacturing research, according to the three parts involved in the problem domain of green manufacturing: manufacturing problems, environmental protection problems, resource optimization problems, people thought that green manufacturing was just the cross part of three sections, so the boundary of the green manufacturing system was the boundary crossed the border of manufacturing system, ecological environment system and natural resources system, which is shown in Figure 2. Along with the intensification of resources and environmental constraints, green manufacturing must develop towards ecological consciousness, which requires that all elements of green manufacturing system should coexist with natural ecology harmoniously. To achieve this goal, green manufacturing system must be in development of integration constantly such as technology integration, resource integration, the integration between enterprises, social integration of production and consumption. With the development of integration of green manufacturing system, the elements of the system change and adjust continuously. The system boundary is dynamically expanded without stopping, eventually there will be a fusion trend between industrial system and social system, ecological environment system, natural resources system. The green manufacturing system shows a tendency of a "pan-border", which is shown in Figure 2. 


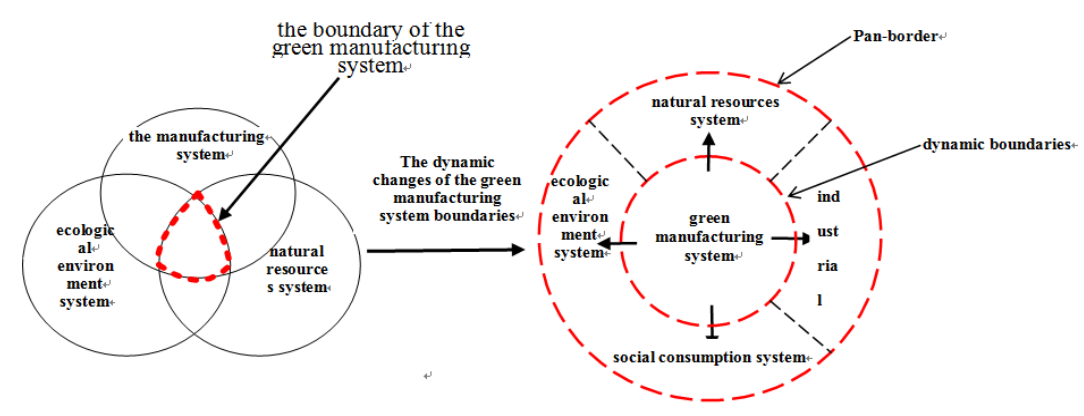

Fig. 2. Dynamic characteristics of green manufacturing system boundaries

\section{DEFINITION OF GREEN MANUFACTURING SYSTEM} BOUNDARIES FINALLY ABBREVIATIONS AND ACRONYMS

Define abbreviations and acronyms are the first time used in the text, even after they have been defined in the abstract. Abbreviations such as IEEE, SI, MKS, CGS, sc, dc, and rms do not have to be defined. Do not use abbreviations in the title or heads unless they are unavoidable. According to the demarcation about boundary types in the shell theory, system boundary has differences between the entity boundary and abstract boundary. So the green manufacturing system also exist entity and abstract boundaries. The entity boundary of green manufacturing system refers to the entities' scope of its activities. The narrow sense of the green manufacturing system boundary refers to the scope of enterprises, while generalized boundary of the green manufacturing system refers to the whole product life cycle or multi-life cycle [7].

The abstract boundary of green manufacturing system has functional boundary, beneficial boundary [8], etc. It is still difficult to define the boundary. Now we will discuss thinking about the definition of green manufacturing system boundary.

\section{A. Boundary impact factors analysis}

According to the analysis above, based on taking resources and environmental problems into account, Material resource constraints, energy constraints and manufacturing environmental constraints codetermine the green manufacturing system boundaries. To define the green manufacturing system boundaries, we should consider about these three aspects, that is, the material resources, energy and manufacturing environmental impact factors.

\section{1) Material resources and energy :}

a) Resources species: Renewable or non-renewable resources, scarce resources or abundant resources, etc.

b) Resource characteristics: Focuses are the environmental impact and price impact of manufacturing resources.

c) Resources consumption: The absolute number of resources consumption, utilization ratio, and attrition rate.

d) Comprehensive utilization ratio of resources.

2) Manufacturing environment: Refers to the effects that manufacturing process and the product whole life cycle or waste after used on the environment.

The environmental impact of green manufacturing refers to ecological impact, environmental impact, and general impacts of a series of problems such as resource utilization, occupational health and safety. Mainly as follows:

Ecological environmental impact: The effects that green manufacturing and its products throughout the life cycle on the ecological environment, such as the "three wastes" in manufacturing process and noise, radiation, and disposal effects on ecological environment.

Occupational health: The harm that all aspects in the process do to the occupational health of laborers through products' whole life cycle.

Security: During products' whole life cycle, the insecurity of equipments and the surrounding environment that caused from failure in all aspects.

\section{B. Defined rules of system boundary \\ 1) Integrity rules:}

Include the integrity of scope and process. The integrity of scope refers that components of system should be fully and completely contained in the discussion of system; the integrity of process rules refers that the impact of various factors about whole life cycle in the manufacturing system has on resources and environment should be fully considered in the analysis of system boundaries.

\section{2) Timeliness principle:}

Timeliness principle is the principle of system green degree evaluation determined by potential objects according to their resources, environment or effects of the energy timeliness. The performance that evaluation objects have on foreign influence is different in term of timeliness. For example, in the manufacturing process of iron and steel enterprises, the impact on the environment and energy intensity is biggish, and disposed electronic product has greater impact than the production process on the environment [9]. Photochemical smog directly affects for two days, while waste plastic naturally degrade for much longer time, we should pay attention to these characteristics when determining the system boundary as well as the potential impact and the high strength impact for a longer time much more.

\section{3) Spatiality principle:}

It refers that according to the influence scope of external space system to determine the boundary of the evaluation system. For example, if greenhouse gas has been produced in the process of product life cycle in the system, the influence of 
space is the whole earth, which is a global effect; if the organic phosphorus has been produced in the process of the product life cycle, the main influence is on local water, which is a local effect. Both effects are obviously different, we must notice this difference when defining the system boundary.

Known from the analysis of the above, green manufacturing system boundaries exist space and time boundary.

Space boundary: Traditional manufacturing system's manufacturing activities are limited within the scope of the enterprise, so its physical boundary is the area of production enterprise, which is within the enterprise; But input of material resources in the system, the "three wastes" produced through manufacturing process and the use process are directly related to the green degree of system. Green manufacturing make the space of traditional manufacturing system much bigger[10], such as the "three wastes" in manufacturing process, the scope of impact involves the natural space outside enterprises, and it has a corresponding space boundary; The rarity of input of material resource in the system also extends the space scope; Multiple enterprise cooperation mode of operation and cloud manufacturing have greatly extend the space of the traditional manufacturing system as well as the exchange of system with the outside world.

Time boundary: In terms of the time dimension characteristics of green manufacturing [5], the environmental impact and resource utilization that whole life cycle and multilife cycle products have involve the time dimension. Product manufacturing, resources consumption, environmental pollution, recycling, and the whole life of the product processing (design, manufacture, use, disposal, etc.) have the green degree evaluation, which make green manufacturing system extended in the aspects of the product's life cycle, thus making the system time boundary extended greatly.

The green manufacturing system boundaries need to have an analysis to define from multiple aspects, such as time and space.

\section{Demarcation method of system boundary}

From the former analysis, based on the consideration of resource and environmental problems, material resource constraints, energy constraints and manufacturing environmental constraints determine the green manufacturing system boundaries, and there exists both the time and space boundary in the system. So we put forward a system boundary definition method for green manufacturing as follows:

Regarding material resources, energy and manufacturing environments as the research objects, analyzing space and time range constraints that material resources, energy and manufacturing environments have on the system in the whole operation process (i.e., product whole life cycle process) of green manufacturing system, thereby gaining space and time boundary in the system.

Material and energy resources acquisition phase: Mainly analyzing the green degree of raw materials and energy, and analyzing their rarity, renewable characteristics and recyclability, etc to determine the time boundary and space boundary.

Clean production phase: In addition to consider time process and space scope of products that from the material into a marketable kind, the time and space boundary should also focus on the time process and space scope of manufacturing environmental impact factors in the manufacturing process, for example, the spatial impact range of exhaust gas, and the length of time that the waste has on soil.

In this phase, the green packaging process should mainly consider the consumption or lack of packaging materials and environmental pollution caused by packaging wastes.

Product use and service phases: First considering energy resource consumption and impact that emissions have on natural ecosystems in the use process of products, then taking the time and space scope impacts that waste products have on natural ecosystems after discard into account

Product recycling and remanufacturing phase: Focus on the environmental impact that products have on manufacture process, and energy resources consumption as well as the impacts that emissions have on natural ecosystems in reuse process.

\section{CONCLUSION}

Through the analysis of resources and environmental constraints for manufacturing system, this paper discusses the boundary and those dynamic characteristics of green manufacturing system within the resource and environmental constraints, to develop the calibration method of the green manufacturing system boundary, on the construction of green manufacturing system, optimization and features of green evaluation is of great realistic significance.

\section{REFERENCES}

[1] Wang Yinlou, Systems Engineering [M]. Beijing: Mechanical Industry Press, 2011

[2] Cao Hongxing, Essence of Shell Theory and its application [M]. Beijing: Science Press, 2011.

[3] Zhang Hua, The Green Manufacturing's System Engineering [M]. Beijing: Science Press, 2012.

[4] Tang Decai, On the Developmental Path of Chinese Manufacturing Industr Based on Resource Restraint [J]. Jiangsu Social Sciences, 2010 (4) :51 58

[5] Zheng Jiliang. Green Manufacturing System's Integration Theory: Based on the Enterprise Clusters Perspective [M]. Yunnan People's Publishing House, 2009.

[6] Xin Xize, Zhu Yaping. System Boundary Research about Green Product Evaluation [J]. Modern Manufacturing Engineering. 2007 (2) :85 88

[7] Guo Yan,Liu Hongchao. Rewview of Key Product Life Cycle Assessment [J].Computer Integrated Manufacturing Systems. 2014 (5) :42 46

[8] Zhang lei. Life Cycle Assessment Boundary Defining the Research to Electrical Appliances Product [J]. Journal of Hefei University of Technology. 2010 (3) : 327 332

[9] You Hongbing. Resources and Environmental Constraints and the Development of China's Manufacturing Industry [J]. Social Scientist,2014(10):25 28

[10] Jin Bei. China's Industrial Development under the Binding of Resource and Environment $[\mathrm{J}]$. China Industrial Economics. 2014 (4) : 5 14. 